\title{
PROCEDIMENTO E EROTISMO NA OBRA DELEUZIANA: CONSIDERAÇÕES
}

\author{
Gabriel Saussen FEIL \\ Universidade Federal do Rio Grande do Sul \\ gabriel.sausen.feil@gmail.com
}

\begin{abstract}
Resumo: 1) O conceito de Procedimento é de suma importância na obra de Deleuze. Não por acaso, os seus autores preferidos são justamente aqueles que criam seus próprios Procedimentos. 2) $\mathrm{Na}$ maioria das vezes, o conceito aparece próximo à temática do Erotismo. Diante dessas duas constatações, o presente artigo objetiva traçar relações entre esses dois conceitos, usando, como estratégia, a escrita por considerações breves (pois acreditamos que Deleuze lida com esses dois conceitos em forma de considerações: não os tomando como objeto central, mas usando-os como modo de proceder diante de seus objetos). A partir de tal relação, concluímos que, em Deleuze, todo Procedimento é Erótico, sendo precisamente por isso que essa expressão se diferencia do sentido comum: quando o Procedimento funciona Eroticamente, distingue-se do manual de conduta. Além disso, concluímos que o Procedimento, apesar de implicar a dissolução das Formas, é, ainda assim, sempre de Formação, alcançando nisso a sua positividade.
\end{abstract}

Palavras-chaves: Procedimento. Erotismo. Transgressão. Deleuze. Formação.

\begin{abstract}
The concept of Procedure is of paramount importance in the work of Deleuze. Not surprisingly, his favorite authors are precisely those create their own Procedures. 2) Most of the time, the concept appears next to the theme of Eroticism. Considering these two findings, this article aims to draw links between these two concepts, using, as strategy, writing by brief considerations (because we believe that Deleuze dealing with these two concepts in the form of considerations: not taking as the central object, but using them as a way of carrying forward of their objects). From the relation, we conclude that, in Deleuze, every Procedure is Erotic and is precisely why this expression differentiate from common sense: when the Procedure works of the Erotic form, distinguishes itself from the manual of conduct. Moreover, we find that the Procedure, although it involves the dissolution of Forms, it is, nevertheless, always Formation, obtaining its positivity.
\end{abstract}

Keywords: Procedure. Eroticism. Transgression. Deleuze. Formation.

\section{Consideração primeira - Das aparições do conceito de Procedimento}

Gilles Deleuze e Félix Guattari usam o conceito de Procedimento em Kafka: por uma literatura menor, afirmando que "somente a expressão nos dá o procedimento" (DELEUZE e GUATTARI, 1977, p. 25). Em Apresentação de Sacher-Masoch, Deleuze apresenta os Procedimentos de condensação e de aceleração, próprios de Marquês de Sade, e os Procedimentos de denegação e suspensão, próprios de Léopold Von Sacher-Masoch (DELEUZE, 1983); em Crítica e Clínica, mostra como Louis Wolfson procede para fazer a língua variar (DELEUZE, 1997).

\section{Consideração segunda - Da preferência pelos autores que criam Procedimentos}


O Procedimento é um conceito de suma importância na produção de Deleuze, agindo diretamente na escolha de seus autores preferidos, no sentido de sempre preferir aqueles que inventam os seus próprios Procedimentos. Quando, em Apresentação de Sacher-Masoch, Deleuze afirma que tanto Sade quanto Masoch não funcionam como autores pornográficos e sim como pornólogos (DELEUZE, 1983, p. 21), é justamente pelo fato de ambos criarem, em seus textos, modos de proceder diante de uma Forma consagrada (os valores morais no caso de Sade; os valores paternais no caso de Masoch). Quando Deleuze afirma que "há processos especificamente masoquistas, independentemente de qualquer reviravolta ou reversão do sadismo" (DELEUZE, 2006, p. 171), está defendendo que o que torna o masoquismo e o sadismo interessantes, é justamente o fato de ambos se constituírem como Procedimentos. Ou seja, Deleuze não se interessa pelo masoquista e pelo sádico num sentido clínico (como a psicanálise, por exemplo), mas se interessa pelo modo singular que cada um deles procede; pelo modo singular que cada um deles faz para agir contra aquilo que os afligem. Deleuze está preocupado com as estratégias que eles criam para ultrapassar as suas doenças.

Por Forma consagrada entende-se, na terminologia deleuziana, estratos; porém, especificamente aqueles que insistem em se perpetuar, que se opõem à primazia dos fluxos. Deleuze e Guattari, em Mil Platôs (DELEUZE e GUATTARI, 1995), afirmam que todo estrato está em processo ininterrupto de desestratificação. Ou seja, segundo eles, não existe estrato parado, sendo por isso que as Formas consagradas são problemáticas: elas contrariam o seu processo natural de deformação. O Procedimento, por sua vez, é justamente a criação de um modo de extrair dessas Formas algo de novo, sob a condição de não simplesmente negálas.

\section{Consideração terceira - Da desmontagem}

Tratando do conceito de Procedimento, em Deleuze, não é necessário dizer: "Procedimento de desmontagem", pois o conceito de Procedimento envolve, necessariamente, a desmontagem. O Procedimento, portanto, diz respeito sempre a um processo de desmontagem de uma Forma (dos processos econômicos e sociais em Kafka, dos valores morais e religiosos em Sade, da função paterna em Masoch, da língua mãe em Wolfson). O Procedimento traça uma nova Forma, porém, faz isso a partir da desmontagem de uma consagrada. Não se trata de uma tarefa crítica (no sentido dialético do termo), mas de uma tarefa que implica a invenção de modos consistentes de fazer os objetos variarem. Em última 
instância, trata-se de um mecanismo que faz funcionar algo que já não funcionava mais, que se encontrava estacionado, triste, morto, representado.

O Procedimento, portanto, não funciona como um protocolo; pelo contrário, é a via alternativa em relação ao manual de conduta ou ao manual de comportamento. $\mathrm{O}$ Procedimento tem aversão a tudo aquilo que dá a entender que as coisas (incluindo os humanos) são sempre iguais. Nesse sentido, o Procedimento teima, por exemplo, com as religiões, precisamente porque elas nos penalizam se por acaso desejamos não permanecer os mesmos.

\section{Consideração quarta - Da positivação do ponto}

Quando Deleuze e Guattari, no platô Três Novelas ou "O que se passou?", falam do ponto (DELEUZE e GUATTARI, 1996), pode parecer que eles o situam em oposição a tudo o que eles desejam: a invenção, o novo, a fuga... Afinal, o ponto é aquilo que já é Formado, localizável, identificável (ele pode ser concebido como sinônimo daquilo que viemos chamando de Forma, porém, ele faz parte de outro desenho, o qual diz respeito à teoria das linhas). A noção de Procedimento, ligada à desmontagem, acaba por mostrar que Deleuze e Guattari nada têm contra o ponto. A questão é que ele é simplesmente doado, pois ele já existe. Uma vez colocado em tona, inicia-se o Procedimento, que é justamente a desmontagem desse ponto. É verdade que essa não é a única maneira de proceder, mas é a maneira Erótica por definição...

\section{Consideração quinta - Da fusão entre Procedimento e Erotismo}

Quando falamos, neste artigo, em Erotismo, estamos nos referindo ao conceito traçado por Deleuze em Klossowski ou os corpos-linguagens (DELEUZE, 2003) e, de maneira mais implícita, na Apresentação de Sacher-Masoch (DELEUZE, 1983). O Erótico aparece como

sendo a dissolução das Formas, dissolução provocada por forças externas a elas. É exatamente quando deixamos de ser, quando o Eu sai de cena, mesmo que somente por um breve instante, que as relações Eróticas aparecem. É quando as Formas são desintegradas. Se a Moral é o que possibilita o Eu, o Erotismo é o que possibilita a sua reinvenção. O Erotismo é um Procedimento, e o Procedimento, por sua vez, é sempre um caso de Erotismo. Ou seja, não se trata de um Procedimento sobre o Erotismo, mas o próprio Erotismo se constituindo num Procedimento, e o próprio Procedimento sendo um caso de Erotismo. Não por acaso, ao entrar na questão do Procedimento, Deleuze acaba, na maioria das vezes, entrando nos autores Eróticos. 


\section{Consideração sexta - Da imitação do Procedimento}

Um Procedimento pode ser sempre imitado sem correr qualquer risco de ser reproduzido, copiado. Queremos dizer que podemos imitar os Procedimentos de Deleuze sem corrermos o risco de fazermos como ele, igual a ele. Basta selecionarmos outra Forma, outro problema. Em suma, podemos imitar um Procedimento de Deleuze, seguindo-o passo a passo, mas se trocarmos de problema, tudo estará mudado.

\section{Consideração sétima - Das maneiras de trair em escritor}

Temos duas maneiras de trair um escritor: imitando o seu modo de fazer, misturando-o a outro conteúdo; imitando o seu conteúdo, misturando-o a outro modo de fazer. A fim de exemplificarmos: o conteúdo de um Procedimento pode não cessar de tomar partido contra Sade, mas a expressão desse Procedimento pode jamais fazer isso: embora o conteúdo libertino de Sade possa estar sendo questionado, o tom da escrita pode ser, ainda assim, libertino. Ou seja, suspende-se no conteúdo enquanto se imita na expressão, num possível efeito dissimulador.

\section{Consideração oitava - Do sexteto Erótico}

Denegação, dissimulação, pantomima, suspensão, hesitação, perversão: eis o sexteto Erótico de Deleuze...

1) A denegação é uma negação positiva. Ela se diferencia da negação: na ansiedade por conquistar o novo, o negador sai logo destruindo o velho. Mesmo dando um passo a mais em relação ao que simplesmente aceita o velho, ele permanece na tarefa crítica (aquela que somente afirma se antes negar). A denegação se torna positiva porque ao invés de destruir o velho, suspende-o.

2) A dissimulação é um deixar que os termos não coincidam. Não exigir, por exemplo, que corpo e linguagem concordem entre si.

3) A pantomima é justamente a prova de uma dissimulação: a do corpo (intuitivo), dizendo não à linguagem (racional).

4) A perversão acontece quando as Formas deixam de ser o que eram.

5) A suspensão é tudo aquilo que antecede e que é posterior a uma Forma. É uma promessa de Forma ou, na maioria dos casos, um informe eterno.

6) A hesitação é o que fica acontecendo no estado suspenso: as matérias ficam hesitando em Ser ou não. 
Esses seis termos não constituem a estrutura Erótica, pois não é disso que se trata. $\mathrm{O}$ Erotismo não depende da união deles (Sade, por exemplo, é um escritor que, embora produza Erotismo, jamais hesita). O Erotismo, em Deleuze, diz respeito a um tomar as Formas (estratos) e com elas fazer outra coisa. Esses seis termos são efeitos de Erotismo, mas não o limitam. Eles também podem ser tomados como possíveis passos de um Procedimento Erótico.

\section{Consideração nona - Do paralelismo entre o corpo e a linguagem}

O sexteto Erótico aparece na leitura que Deleuze faz dos romances de Pierre Klossowski (DELEUZE, 2003):

Klossowski quer a suspensão (entendida como o estado indiscernível das coisas): toda a sua escrita tende para isso. Para alcançá-la, usa a estratégia da reflexão, a qual, por sua vez, implica um paralelismo entre o corpo e a linguagem. Se há um paralelismo, é porque ao invés de haver uma relação de oposição entre os dois termos, há uma pressuposição recíproca. O corpo e a linguagem são flexões; quando relacionados entre si são reflexões. De modo que na reflexão, a flexão, de ambos, vê-se desdobrada, aberta, sem cobertura, liberada de tudo aquilo que a reduz ordinariamente (DELEUZE, 2003, p. 294, 295): encontra-se em suspensão. Ao flexionar, dobra, ao reflexionar, desdobra, abrindo-se para o indiscernível. A flexão afirma, porém, sozinha, encerra; a reflexão afirma e mostra que nada está acabado. E como é o corpo que reflexiona a linguagem (pantomima), e é a linguagem que reflexiona o corpo, o Erotismo em Klossowski diz respeito à comum reflexão desses dois termos, visto que é nessa comum reflexão que tudo é jogado aos espíritos, onde tudo passa a ser pervertido. Corpo e linguagem se dissimulam simplesmente porque, embora estejam juntos, não condizem jamais: um não cessa de trair o outro.

Por que Klossowski quer a suspensão? 1) Nada há de perverso no negar aquilo que nos parece Formado. Negando ou não, novas Formas irão, naturalmente, surgir (o processo de deformação não cessa jamais); mas, no Erotismo de Klossowski, a questão é retardar as determinações: quanto mais hesitarmos para determinar Formas, mais pairaremos com os espíritos. 2) Quando nos limitamos a conhecer algo apenas a partir do modo que já a conhecemos, acabamos conhecendo de um modo muito triste, visto que quando se tem um só, esse tende a ter que suprir determinadas expectativas. Apenas se possui bem aquilo que já é possuído pelos espíritos, aquilo que já não tem determinação, aquilo que é expropriado, posto fora de si, denegado. Uma vez posto para fora de si, é possível encontrar, enfim, algo totalmente desvinculado daquele referido modo triste. 3) Há, no Erotismo de Klossowski, 
toda uma teologia: é que a teologia é a ciência das entidades não existentes, no sentido de ainda não Formadas: as Formações (incluindo as personalidades) pertencem à ordem de Deus, a qual é inimiga da ordem dos espíritos, que é a ordem das indeterminações (nesse sentido, trata-se, antes, de uma desordem). Deus quer conservar as Formas: as identidades, os Eus, os saberes, a tradição e tudo aquilo que concentra forças para torná-las facilmente reconhecíveis. Deus abocanha os outros deuses, mais conhecidos como demônios (ou espíritos, ou elementos indeterminados), para julgá-los ao seu gosto. A ordem de Deus cria estrias e essas passam a ser consideradas a Existência, de modo que todas as indeterminações, que escapam dessas estrias, passam a ser desconsideradas ou, por serem estranhas, evitadas: eis aí a criação da maldição, dos malditos. Acontece que as indeterminações têm má vontade em relação à tarefa de Deus. Essa má vontade é óbvia, visto que as indeterminações se misturam naturalmente com as Formações. Então é também óbvio que apareçam Formas que, embora tenham sido selecionadas pelas estrias, rebelem-se e se revoltem contra essa ordem absurda. As rebeldes não deixam esquecer que as selecionadas continuam se constituindo por indeterminações, e isso faz implodir a ordem de Deus. A ordem da perversidade implode a ordem de Deus, e isso não é raro de acontecer, visto que a ordem de Deus é somente uma derivada daquela. A diferença entre as ordens, portanto, não é a de Deus ordenado de um lado e de espíritos desordenados de outro, um alto mundo e outro baixo. Só o que há são espíritos desordenados, e no mundo organizado o que há são espíritos ainda indeterminados, porém, momentaneamente estriados (Formados). Espíritos maus que violentam, entram vários no mesmo corpo e um só possui vários corpos: orgia. Eis aí o desejo de Klossowski.

\section{Consideração décima - Da transgressão}

Somente há Erotismo onde há transgressão: ela é a operação Erótica. Mas essa operação não acontece se não houver uma Forma (quanto mais consagrada melhor). É que a transgressão diz respeito a um processo de insistência, nunca de abandono: ninguém transgride saindo fora. Para transgredir é necessário insistir com as Formas que nos aborrecem, na esperança de que essas Formas sejam desmontadas.

\section{Consideração décima primeira - Do Erotismo não se constituir num fim}

É curioso como se repete entre os escritores Eróticos o fato de todos eles traçarem um plano: seja via contrato, via projeto ou via pacto. Não se trata de uma mera coincidência, o plano é a condição para que o Erotismo de que tratamos se realize. O objetivo último desse Erotismo jamais se encontra no fazer Erotismo por fazer, mas sempre no diluir os papéis 
prontos. O conteúdo dito Erótico não funciona como um fim, mas funciona como a consistência de uma estratégia que visa outra coisa. Se o Erotismo fosse um fim, não seria necessário um plano, bastaria uma linguagem obscena por si só. É precisamente aí que os pornólogos se distinguem dos pornográficos. Estes têm o Erotismo como fim; aqueles não visam o Erotismo, visam outra coisa, elevando o Erotismo a uma função superior: 1) $O$ conteúdo Erótico funciona chamando a atenção e preparando os corações. 2) $\mathrm{O}$ enredo, às vezes sendo uma narrativa, funciona como uma estratégia, uma engenhoca. 3) O novo é o fim, é o visado. 4) O Erotismo, propriamente dito, é o Procedimento, o qual envolve os três elementos anteriores.

Os planos Eróticos, portanto, não formam um gênero, o gênero Erótico, pois o Erotismo não funciona, ao menos para os pornólogos, como um gênero, mas como um modo de proceder. O Erotismo é um Procedimento que dilui as Formas em função de uma suspensão.

\section{Consideração décima segunda - Da organização das indeterminações}

O Procedimento não quer, simplesmente, desorganizar as Formas, pelo contrário, quer instituir uma ordem. O Procedimento é uma instituição, no sentido de colocar ordem nas indeterminações que nos impulsionam. A questão, a grande questão, é criar uma ordem aos impulsos de tal maneira que eles não sejam negados, mas afirmados. O Procedimento é um interrogatório que parte do vazio, fantasiado de lista universal de respostas. (Não interessa qual é o foco: pode ser uma foto, um livro, uma Instituição, a linguagem, a escrita, o Eu...). O Procedimento é, primeiramente, uma maneira de ocupar o vazio provocado pelas Formas doentes. Depois, é uma maneira de recuperar o vazio. Em suma, o Procedimento é uma maneira de preencher o vazio sem se desfazer dele.

\section{Consideração décima terceira - Dos libertinos}

Um exemplo de Procedimento que institui uma ordem é o Procedimento libertino: o libertino é um decorador, um diretor de teatro. A sua questão não está tanto no que ele diz, mas no modo em que dirige a vida cotidiana dele e dos demais envolvidos. Para identificar um libertino, basta identificar quem é que detém a direção da cena. Como um diretor, o libertino cumpre todo um protocolo, tomando o cuidado de fazer acontecer o prazer ordenado. Um libertino é valorizado por sua engenhosidade e por sua intelectualidade, e jamais por deixar tudo acontecer. Se ele é um criador de Procedimento não é porque simplesmente perverte os manuais de conduta, mas é porque ele não faz isso sem instituir um novo modo de 
proceder. Ou seja, o libertino recebe esse nome não porque é adepto da liberdade ou da bagunça, mas porque é adepto da liberdade de criar novas ordenações. Nesse sentido, o Procedimento nada tem contra as ordens; ele é contra as ordens que não foram criadas precisamente por aquele que as cumpre.

Os libertinos têm um código. Por exemplo, as classes que distinguem a função dos libertinos da função das vítimas, em 120 dias de Sodoma (SADE, 2006), nada são senão um código. Entretanto, esse código não tem referência às classes morais ou sociais, mas às classes que se definem no interior da Sociedade Libertina. Os códigos que os desagradam são aqueles que somente funcionam se desconsiderarem um elemento intrínseco à natureza: o impulso. Nada contra os códigos, mas contra aqueles que sinalizam contra a natureza. Se os libertinos odeiam as leis, é porque elas são do tipo de código recém mencionado. E se têm horrores aos homens das leis, é porque esses são fracos, submetem-se às leis, deixando que ela trabalhe por eles. A lei é repudiada quando ela substitui a arte de julgar, quando a lei toma conta e ela mesma julga autonomamente.

\section{Consideração décima quarta - Das linhas}

A tarefa de inventar Procedimentos pode não interessar à maioria, pois a ela interessa somente a pequena fatia do mundo que lhes foi apresentada. O Procedimento importa somente àqueles que querem ver mais, embora no clímax, não haja mais nada para se ver. $\mathrm{O}$ Procedimento não deve ser usado para fugir da realidade, pelo contrário, deve ser usado, pois é assim que ele funciona, para alargar a realidade. Se fôssemos fazer o Procedimento funcionar dentro da teoria das linhas de Deleuze e Guattari (DELEUZE e GUATTARI, 1996), a sua linha, por excelência, não seria a de fuga, mas a molecular, aquela que nos disponibiliza algum tipo de controle sobre ela, a partir da sua flexibilidade. A linha de fuga seria a meta do Procedimento, aquela que somente daria o ar de sua graça em caso de êxito. Se as linhas de fuga e molecular nos interessar menos do que a molar, é sinal de que devemos parar de inventar Procedimentos. Então simplesmente paremos, pois devemos ter cansado de desejar variações. O Procedimento expressa sempre uma nova Forma que deve inventar alguma coisa para permanecer sendo nova.

\section{Consideração décima quinta - Do inesperado no Procedimento}

O Procedimento não alcança o seu clímax devido ao seu empreendimento racional: só o inesperado pode fazer isso. Se somente mestres podem se aventurar com Procedimentos, é porque o comportamento desses que se aventuram pode ser comparado ao do químico que 
verte uma última gota numa certa preparação, em que passada essa última decisão, nada mais pode ser modificado (MILLER, 1991, p. 51). Considerando que o Procedimento seja eficiente, temos, portanto, duas certezas: 1) tudo terá sido transformado, tudo terá tomado uma nova Forma; mas se transformado no quê? 2) Não há como prever. Podemos, com muita competência, saber controlar o Procedimento, mas jamais poderemos controlar os seus efeitos. Em outros termos: podemos criar as condições para que o Procedimento se efetue, porém, jamais podemos controlar o inesperado. É que o Procedimento não funciona como uma teoria, mas como um problema de vida.

\section{Consideração décima sexta - Da expressão}

O Erotismo é menos interessante nos seus conteúdos, e mais interessante nos seus modos de expressão. Se Sade escolhesse falar sobre outros assuntos, mas mantivesse os seus Procedimentos de insistência, talvez não perdesse nada de sua força de escrita. É por isso que o Erotismo não pode se limitar a um assunto (à obscenidade, por exemplo); ele ultrapassa a questão temática: é o modo de fazer algo proceder. Trata-se da prática secreta do indireto: intransitivo que é, o Erotismo se abriga nas malhas do transitivo, do discurso sobre alguma coisa. O Erotismo não se diz, não se vê, não se percebe; a única exceção é quando ele encontra um hospedeiro: uma Forma qualquer.

\section{Consideração décima sétima - Da violência Erótica}

Embora o Erotismo violente as Formas pretensamente acabadas, ele necessita, ainda assim, dessas Formas: ao menos de uma. Ora, é que para experimentar o Erotismo é preciso esse mínimo: sem Formas não há transgressão e a Erotização se torna impossível. E é por isso que todo projeto Erótico implica a escolha de um objeto, objeto esse que suscita o crime. Se tudo ocorrer bem, a conseqüência é a transformação desse objeto, bem como a do autor do crime, num efeito de reflexão. As Formas exemplares são as mais pretensiosas, aquelas que, ao agonizarem, provocam suspiros. A perversidade do Erotismo aparece justamente quando se quer negá-la, quando se quer fazer de conta que algo é imutável. Talvez seja por isso que Deleuze diz que para Klossowski nada é mais pornográfico do que a dissolução do Eu (DELEUZE, 2003), afinal, nada mais pretensioso do que a idéia de Eu. Os personagens de $O s$ 120 dias de Sodoma (SADE, 2006) são modelos nesse sentido: os amigos libertinos fazem com que as donzelas e os donzelos se casem entre eles. Mas por que fariam isso se eles são expressamente contrários à Instituição do Casamento? Ora, efetuam os casamentos com o 
único propósito de ter uma Instituição a mais para descumprir. Ou seja, primeiro uma Forma, depois fazer com ela o que o espírito desejar.

\section{Consideração décima oitava - Do masoquismo}

O Erotismo no masoquismo está no fato do masoquista destruir a si mesmo. Em outros termos: a Forma a ser pervertida está no próprio criador do Procedimento: o masoquista. Trata-se de planejar a perversão de si mesmo. De qualquer maneira, o mistério continua: por que destruir a si próprio? Os críticos, segundo Deleuze (DELEUZE, 1983), não encontram sentidos porque somente são capazes de enxergar um aspecto negativo na destruição, não sendo capazes de imaginar, sob um aspecto positivo, que a destruição possa produzir algo de novo. É comum ouvir dizer do narcisismo no masoquismo, afinal, toda a questão está no Eu, mesmo que seja para destruí-lo. Ora, fazer o quê se é justo o Eu que está a aborrecê-lo?

\section{Consideração décima nona - Da Formação}

Em Apresentação de Sacher-Masoch, Deleuze nos apresenta, segundo ele, o grande educador: Sacher-Masoch (DELEUZE, 1983). Em consideração a isso, Sandra Mara Corazza, em seu texto intitulado Uma única vez, diz ser essa "a única vez em que Deleuze fala em aprendizagem" (CORAZZA, 2006, p. 42), como relação pedagógica. Constatação importante, visto que Deleuze não tem a educação como interesse. A questão: por que é que a única vez em que Deleuze fala sobre isso, é quando o seu interesse é o Erotismo, e mais precisamente o masoquismo?

Em primeiro lugar, é preciso dizer que, ao falar em aprendizagem, Deleuze não está se limitando à aprendizagem Institucional. Em segundo lugar, se a aprendizagem está relacionada com o Erotismo, é justamente porque, para Deleuze, a aprendizagem, por ser sempre uma violência, implica a perversão. Em terceiro lugar, a relação com o masoquismo se dá porque o sucesso desse projeto depende da capacidade do masoquista de Formar uma carrasca fria e severa: o suficiente para não se deixar condicionar pelos sentimentos do homem. Toda a questão educativa está aí: é preciso Formar essa carrasca, persuadi-la a se aliar com o seu projeto, "de modo a parecer que é ela quem educa o educador, embora seja este quem a forma" (CORAZZA, 2006, p. 40). Masoch funciona como um educador, portanto, porque o seu projeto masoquista pressupõe a Formação de sua carrasca.

O masoquista apanha para suprimir a sua semelhança com os papéis prontos, já estabelecidos (eis aí a perversão). Apanha para fazer nascer um novo homem (eis aí a Formação). Eis aí a positividade desse Procedimento masoquista: ele Forma uma carrasca, 
porém, faz isso em função de sua própria dissolução. Ele cria uma nova Forma para se refletir nela: uma vez refletido, nasce um novo homem. Em outros termos: o Procedimento masoquista não nega o Eu, pois não o destrói, apenas o suspende para que ele experimente um novo nascimento.

\section{Referências}

CORAZZA, Sandra Mara. Uma única vez. In: Artistagens: filosofia da diferença e educação. Belo Horizonte: Autêntica, 2006, p. 37-42.

DELEUZE, Gilles. Apresentação de Sacher-Masoch: o frio e o cruel. Rio de Janeiro: Taurus, 1983.

Crítica e Clínica. São Paulo: 34, 1997.

. Klossowski ou os corpos-linguagens. In: Lógica do Sentido. São Paulo: Perspectiva, 2003, p. 289-309.

Mística e masoquismo. In:

A ilha deserta: e outros textos. São Paulo: Iluminuras, 2006.

DELEUZE, Gilles; GUATTARI, Félix. Kafka: por uma literatura menor. Rio de Janeiro: Imago, 1977.

_. Mil Platôs vol 1. Rio de Janeiro: 34, 1995.

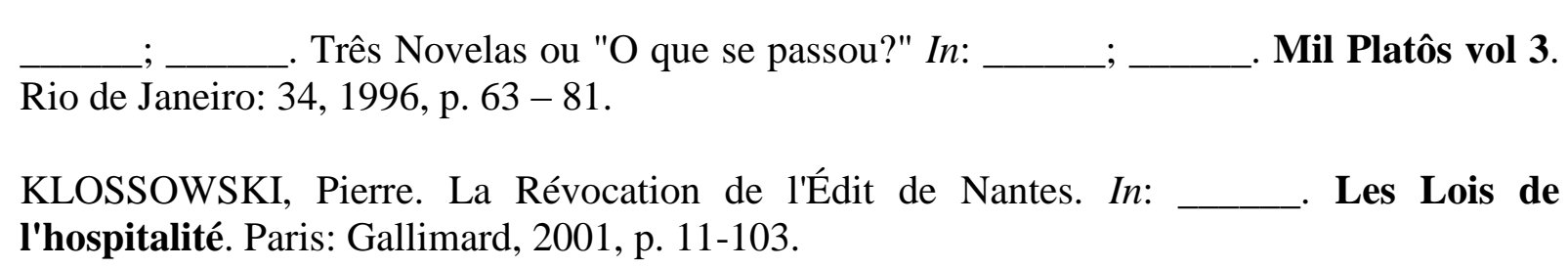
105-173.

Roberte, ce soir. In:

Les Lois de l'hospitalité. Paris: Gallimard, 2001, p.

Le Souffleur. In:

Les Lois de l'hospitalité. Paris: Gallimard, 2001, p. 175332.

MILLER, Henry. Obscenidade e reflexão. s/l: Vega; Passagens, 1991.

SACHER-MASOCH, Léopold Von. A Vênus das peles. In: DELEUZE, Gilles. Apresentação de Sacher-Masoch. Rio de Janeiro: Taurus, 1983, p. 145-301.

SADE, Marquês. Os 120 dias de Sodoma ou A escola da libertinagem. São Paulo: Iluminuras, 2006. 